\title{
Development of Pneumatic Deformability Test of Polylactic Acid Films
}

\author{
Dániel GERE, ${ }^{1,2}$ Kornél PÖLÖSKEI ${ }^{3}$ \\ ${ }^{1}$ Budapest University of Technology and Economics, Faculty of Mechanical Engineering, Department of \\ Polymer Engineering, Budapest, Hungary, gered@pt.bme.hu \\ ${ }^{2}$ IMSYS Ltd, Material Testing Laboratory. Budapest, Hungary \\ ${ }^{3}$ Budapest University of Technology and Economics, Faculty of Mechanical Engineering, Department of \\ Polymer Engineering. Budapest, Hungary, poloskei@pt.bme.hu
}

\begin{abstract}
The aim of the present study is to develop a test method suitable for modelling thermoforming processes and which provides an index that accurately characterises the thermoformability of a film or sheet at a given temperature and pressure. For this purpose, the elevated temperature pneumatic deformability test was considered to be the most suitable. During the test, the film is blown until it tears, which takes only a few seconds. We recorded blowing during the test, and used the images to determine the ascent $(\mathrm{k})$ of the specimens and approach the estimated surface of the deformed specimens with a sphere.
\end{abstract}

Keywords: polylactic acid, thermoforming, pneumatic deformability test, Burgers model.

\section{Introduction}

Due to environmental efforts, natural-based polymers are gaining ground. Among biopolymers, polylactic acid (PLA) stands out due to the amount used and its favourable mechanical properties [1-3].

In the $21^{\text {st }}$ century, the tremendous increase in transport of goods has brought with it the explosive development of the packaging industry, which in turn has led to the prominence of thermoforming technologies [4-7].

For most polymer processing technologies, indicators are available that can be used to characterise the processability of a polymer directly. In contrast, vacuum forming and pressure forming do not have such an indicator. There is no simple property that provides direct information about the processability of a film or sheet with thermoforming technologies. The aim of the present study is to develop a test procedure suitable for the accurate determination of such an indicator. Previously, there have been experiments to model thermoforming by elevated temperature ball burst tests, which, although they provided an accurate force-displacement curve, have not provided a clear indicator. The dynamics of the ball burst test also lagged far behind the practical speed of hot forming. However, the elevated temperature pneumatic deformability test makes it possible to track higher-rate deformation easily [5-7].

The dynamics of the pneumatic deformability test are much closer to the practice of thermoforming. The aim of the study is to investigate the applicability of this method.

\section{Materials and processing}

The investigated film was manufactured at the Department of Polymer Technology of the Budapest University of Technology and Economics with a Labtech LCR 300 flat film line (Labtech Engineering Co., Ltd.). We used extrusion-grade PLA type Ingeo Biopolymer 2003D from NatureWorks LLC. The screw speed of the single-screw extruder was $54 \mathrm{rpm}$. The temperature profile of the extruder from the first zone to the die was 165-165-170-175-180 ${ }^{\circ} \mathrm{C}$. The temperature of the coat-hanger die was $180^{\circ} \mathrm{C}$. The temperature of the tempered rollers was $60^{\circ} \mathrm{C}$. The rotation speed was $0.6 \mathrm{~m} / \mathrm{min}$, and the draw speed was $1 \mathrm{~m} / \mathrm{min}$. The film had a nominal thickness of $500 \mu \mathrm{m}$. The glass transition temperature was $55^{\circ} \mathrm{C}$. 


\section{Test method}

\subsection{Test arrangement}

The main part of the equipment is a mould made of AlMgSi 6061 alloy (Figure 1). The mould has two parts, between which we place the sheet or film to be tested. The lower mould half includes a sealing groove into which an O-ring is inserted and a hole for the introduction of compressed air. The upper mould half is replaceable. A smaller or a larger measuring hole half mould can also be used. The smaller measuring mould half has a hole of $79.8 \mathrm{~mm}$ in diameter, and the larger measuring mold half has a $112.8 \mathrm{~mm}$ diameter hole. The $79.8 \mathrm{~mm}$ diameter measuring mould half (Dm) was used for the tests. This is because the films tend to slip out of the larger diameter measuring mould half during the test. The two mould halves are connected to each other with four M8×18 holes and four M8 screws.

The device was connected to the wall compressed air network, which meant a 9 bar pressure. The compressed air entered a pressure control valve through an $8 \mathrm{~mm}$ outer diameter polyurethane (PU) pneumatic tube. After the pressure control valve, a pressure measuring unit was installed and then a shut-off valve. After the shutoff valve, an $8 \mathrm{~mm}$ outer diameter pneumatic tube led into the mould, which was connected to the mould with a G 1/4" fitting. The test arrangement is shown in Figure 2.

\subsection{Measurement process}

During the tests, the mould for the pneumatic deformability test was placed in the heating chamber of a Zwick Z250 universal tensile tester at a specified temperature for $15 \mathrm{~min}$. Before starting the test, we opened the heat chamber door, and then, using a Nikon D3200 camera, we recorded the behaviour of the films at a given pressure. In these tests, the failure height of the films, the failure mode, and the symmetry of the formed „bubble” were the primary characteristics to be analysed.

The test arrangement was as follows. The pneumatic deformability testing mould was located on the lower half of the heating chamber so that the top plate of the mould was at a height of $800 \mathrm{~mm}$. The camera was mounted on a camera tripod and positioned $50 \mathrm{~mm}$ above the plane of the top plate of the mould at a height of $850 \mathrm{~mm}$ and at a distance of $700 \mathrm{~mm}$ from the centre plane of the mould. A measuring scale was placed $40 \mathrm{~mm}$ behind the mould. The zero points of the measuring

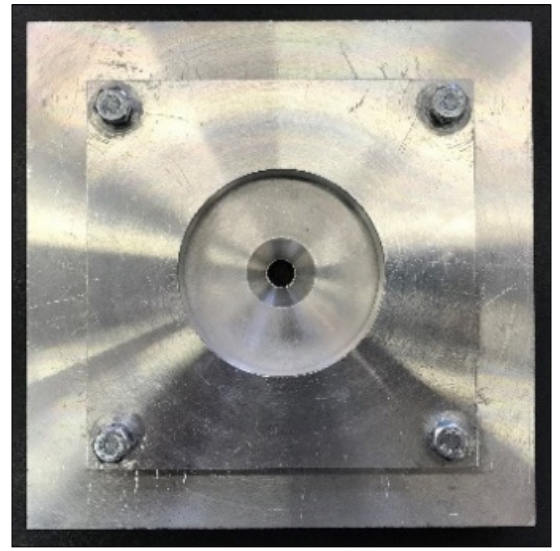

Figure 1. The mould used for the pneumatic deformability test.

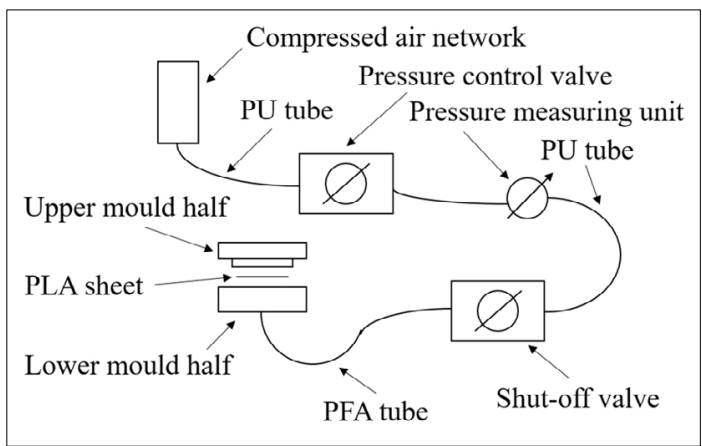

Figure 2. The test arrangement.

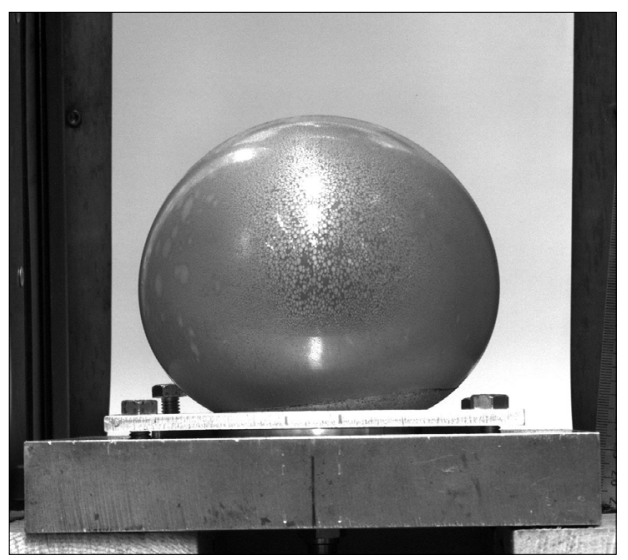

Figure 3. A measurement frame of PLA 2003D film before failure.

scale were in line with the plane of the film between the two mould halves.

Figure 3 shows a measurement frame. Videos were recorded at 25 frames per second. To determine the failure of the films, we took the frame before the first crack appeared, or the frame 
where the „bulge” that caused the failure first appeared.

As the test sample and the measuring scale are located in two separate planes, the readings taken from the frames have to be corrected. The corrected value can be calculated with equation (1).

$$
\tan \beta=\frac{Y_{1}-50}{X_{1}}=\frac{Y^{*}}{X_{2}}
$$

By rearranging equation (1), we obtain equation (2).

$$
Y^{*}=\frac{X_{2} \cdot\left(Y_{1}-50\right)}{X_{1}}
$$

In this case $X_{2}=140 \mathrm{~mm}$ and $X_{1}=740 \mathrm{~mm}$. $Y_{1}$ is the read off value and $Y^{*}$ is the distorted part of this value. Thus, the obtained correction equation is (3):

$$
Y_{m}=Y_{1}-0,16667 \cdot\left(Y_{1}-50\right) \text {, }
$$

where $Y_{m}$ is the actual height of the „bubble”. The geometric model used for the distortion is shown in Figure 4.

During the tests, the sample was fixed between the lower and upper mould halves of the pneumatic deformability device and then remained at a given temperature in the heating chamber for 15 minutes, during which the temperature of the test piece approached the temperature of the heating chamber.

\section{Results and discussion}

The samples were placed in a heat chamber tempered to $90^{\circ} \mathrm{C}$. Prior to the tests, our goal was to determine the failure height of the film. However, during the tests, we found that, with the exception of one specimen, the films did not suffer any destructive deformation under a pressure of 1 bar. However, the degree of deformation suffered from a pressure of 1 bar can still provide useful information. The formed „bubble” was approximated by a sphere, the symmetry of which was characterised by the quotient of two diameters enclosing $\pm 45^{\circ}$ with the centerline of the „bubble”. The placement of the lines used to characterise the symmetry at $45^{\circ}$ to the centerline was intended to eliminate mould distortion. This ratio shows a high degree of symmetry for a value around one. The position of the dimensions is shown in Figure 5. To determine $d_{1}$ and $d_{2}$, we used the GIMP open-source image editing program. Using the scale bar in the background of the frames, we divided the number of pixels between two divisions by the corrected value of the distance between the two divisions. Then, on the centerline of the mould, down from the top line of the „bubble”, we selected the point corresponding to half of $k$. Starting from that point, we read the number of pixels between diameters $d_{1}$ and $d_{2}$. The number of pixels was multiplied by the distance between the pixels in the divisions of the scale bar. The height column in Table 1 and 2 already shows the corrected value.

The results of the tests at 1 bar are shown in Table 1.

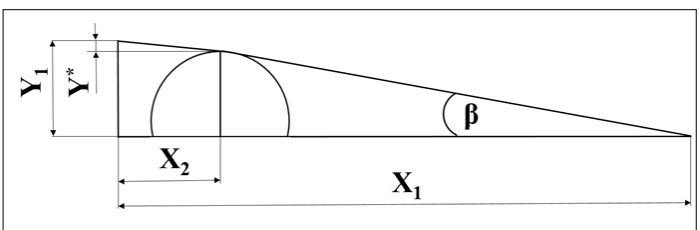

Figure 4. The geometric model.

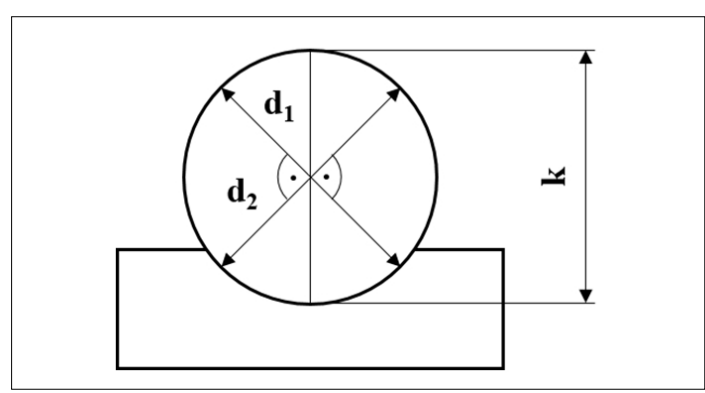

Figure 5. Position of the dimensions

Table1. Measured data of PLA 2003D film at 1 bar.

\begin{tabular}{|c|c|c|c|}
\hline Sample & $\begin{array}{c}\text { Ascent k } \\
(\mathbf{m m})\end{array}$ & Failure & $\mathbf{d}_{\mathbf{1}} / \mathbf{d}_{\mathbf{2}}$ \\
\hline 1. & 124.99 & yes & 0.994 \\
\hline 2. & 120.83 & no & 1.010 \\
\hline 3. & 119.17 & no & 0.996 \\
\hline 4. & 104.33 & no & 1.047 \\
\hline 5. & 103.33 & no & 1.004 \\
\hline
\end{tabular}

Table 2. Measured data of PLA 2003D film at 2 bar.

\begin{tabular}{|c|c|c|c|}
\hline Sample & $\begin{array}{c}\text { Ascent } \mathbf{k} \\
(\mathbf{m m})\end{array}$ & Failure & $\mathbf{d 1} / \mathbf{d} 2$ \\
\hline 1. & 141.67 & yes & 1.013 \\
\hline 2. & 139.17 & yes & 1.010 \\
\hline 3. & 152.50 & yes & 0.979 \\
\hline 4. & 121.67 & no & 0.968 \\
\hline 5. & 113.33 & no & 1.025 \\
\hline
\end{tabular}


The data show that the forming limit of the film after 15 minutes at $90^{\circ} \mathrm{C}$ is slightly above $120 \mathrm{~mm}$ at 1 bar. The results of the tests at 2 bar are shown in Table 2.

The test results at two different pressures indicate that the $500 \mu \mathrm{m}$ film "bubble" of PLA type 2003D is symmetrical with good approximation.

The videos provided an opportunity to examine the elongation of the films over time. Video recordings contain 25 frames per second. To analyse „bubble” formation, we chose the frequency of the images taken from video according to how fast shaping took place-so that the obtained curves would correspond to the process of „bubble formation” and have a consistent appearance.

Every tenth frame was chosen during the characterisation of the forming of the PLA 2003D "bubble" at 1 bar. Considering the frame rate, it means a sampling of 2,5 images per second. We plotted the increase in „bubble” height in an ascent-time diagram (Figure 6).

The resulting ascent curve resembles a logarithmic function, followed by a horizontal line, where ascent stabilized-in this experiment, the film did not fail.

We used every fourth frame to evaluate the PLA 2003D sample at 2 bar. It means sampling at every 0.16 second. The more frequent sampling was justified by the fact that the PLA 2003D failed in about 3 seconds due to the pressure of 2 bar. The ascenttime diagram is shown in Figure 7.

In the case of 2 bar, the ascent curve is nearly linear after the initial rapid deformation. In the case of 1 bar, ascent stabilised at a fixed value since the bubble did not fail.

From the measured ascent-time diagrams, we attempted to determine the parameters of a model analogous to the Burgers model describing the

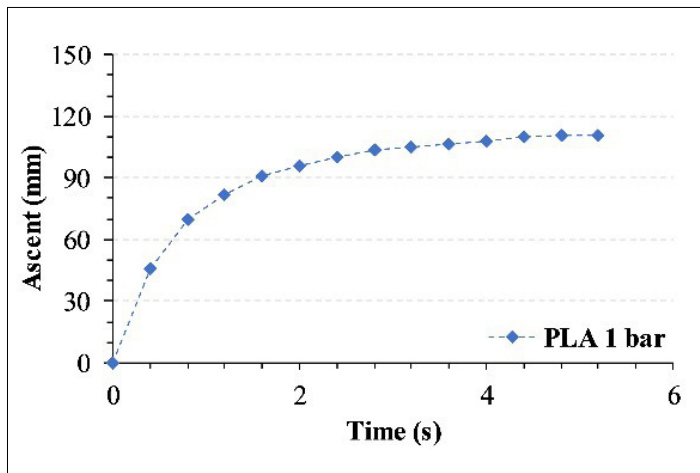

Figure 6. Ascent-time diagram of the PLA 2003D sample at 1 bar deformation of films. The vertical axis of the diagram must be transformed from ascent to surface elongation to determine the parameters of the model. The elongation of the film surface $\varepsilon$, was defined (6) as the quotient of the initial area of the film $A_{m}$ (4) and the surface area of the sphere with a diameter corresponding to the given ascent: $A_{h}$ (5).

The applicability of this model is significantly limited by modelling the surface of the „bubble” as a sphere when surface elongation is calculated. It contains significant neglections due to mould-induced distortions. In the initial stage of forming, the surface of the film has a paraboloid shape-approximating it with a sphere results in a significant error, therefore surface elongation was interpreted only above an ascent of $50 \mathrm{~mm}$. Based on the experiments, this is the minimum height above which the resulting „bubble” can be properly approximated with a sphere. The definition of the elongation of the film with the surface was justified by the fact that in thermoforming technologies, the surface of the forming mould is a measurable and important feature of the mould.

$$
\begin{aligned}
& A_{s z}=\frac{D_{s z}^{2} \cdot \pi}{4} \\
& A_{b}=\frac{4 \cdot k^{2} \cdot \pi}{4} \\
& \varepsilon=\sqrt{\frac{A_{b}-A_{s z}}{A_{s z}}}
\end{aligned}
$$

To calculate the parameters of the Burgers model, we also need to define an initial stress $\left(\sigma_{B}\right)$. To determine the stress (9), we divided the force exerted in the open area of the mould $\left(A_{m}\right) F(8)$ by

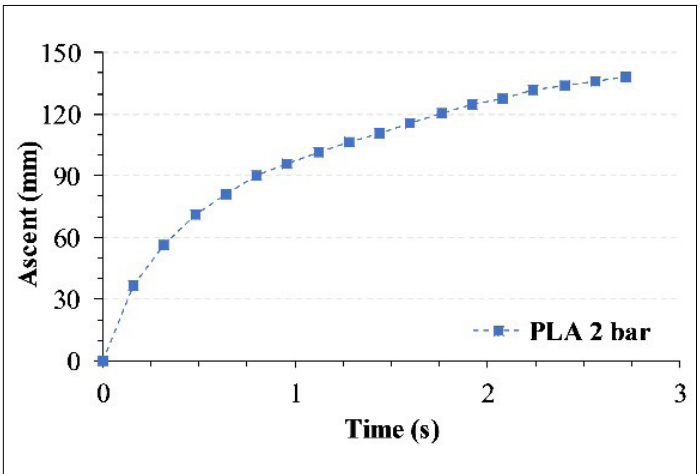

Figure 7. Ascent-time diagram of the PLA 2003D sample at 2 bar 
the cross-section $\left(A_{f}\right)$ exposed to the shear stress at the beginning of film formation. This is the product of the circumference $\left(D_{m}\right)$ of the forming mould and the thickness $(v)$ of the film (7).

$$
\begin{aligned}
& A_{f}=D_{s z} \cdot \pi \cdot v \\
& F=A_{s z} \cdot p \\
& \sigma_{B}=\frac{F}{A_{f}}
\end{aligned}
$$

We can calculate the model parameters from the transformed surface elongation curve and the obtained stress. The calculation of model parameters was constructed from the surface elongation-time diagrams. A typical surface elongation response curve transformed from surface elongation is shown in Figure 8 for PLA 2003D at 2 bar.

We neglected the instantaneous elastic deformation component when we determined the parameters of the model, as although the material has instantaneous elastic deformation in its rubbery state, this deformation is negligible compared to the other components. As a result, parameter $E_{1}$ is dropped from the model.

The equation of our model calculated from a 2 bar load for PLA 2003D (10):

$$
\varepsilon_{\ddot{o}}=\frac{\sigma_{B}}{12,997} \cdot t+\frac{\sigma_{B}}{4,836} \cdot\left(1-e^{-\frac{1,547 \cdot t}{4,836}}\right)
$$

The aim of our model was to calculate expected surface elongation $\left(\varepsilon_{s}\right)$ as a function of time $(t)$ for other loads $\left(\sigma_{B}\right)$ on the basis of the model. We checked the accuracy of the model determined with the 2 bar specimen using the forming data of the 1 bar specimen. The forming of the test sample tested at 1 bar took 5.2 seconds. The stress

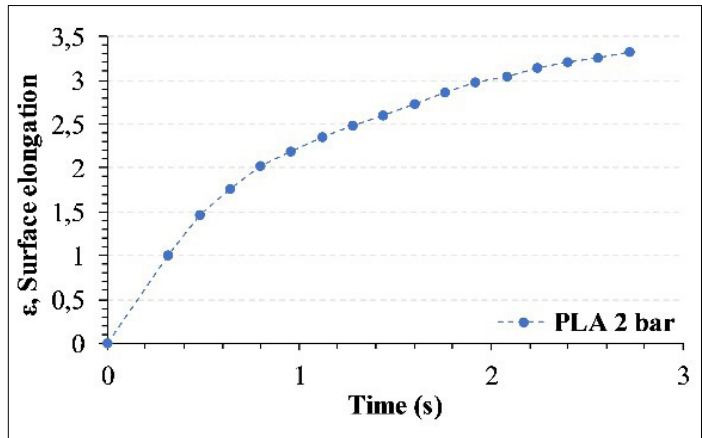

Figure 8. Surface elongation-time diagram of the PLA 2003D sample at 2 bar. in the film at 1 bar was $3.98 \mathrm{MPa}$. Putting these values into the model, we get the expected surface elongation 2.27. In contrast, the real surface elongation of the film was 2.77 .

\section{Conclusions}

In our study, we proved that the elevated temperature pneumatic deformability test is suitable for modelling thermoforming processes. We have determined a simple index, the ascent $(k)$, the maximum value of which is an excellent indicator of the thermoformability of a film or sheet at a given temperature and pressure. This simple index helps to determine the maximum deformability with a good approximation under uniform bi-axial loading. Our results are validated by the fact that the elongations calculated from the ascent can be plotted as a function of time, and the resulting curve fits the Burgers model perfectly. In continuing the research, it is necessary to explore the effect of each neglection, such as the geometric approximation with a sphere or the change of wall thickness distribution as a function of time.

\section{Acknowledgements}

This research was supported by The National Research, Development and Innovation Office (grant number NVKP_16-1-2016-0012). Dániel Gere expresses his gratitude for the Cooperative Doctoral Programme of the Ministry of Innovation and Technology of Hungary. We are grateful for the assistance of András Dénes, a BSc student, in performing the tests.

\section{References}

[1] Gere D., Czigany T.: Future trends of plastic bottle recycling: Compatibilization of PET and PLA. Polymer Testing, 81. (2020) 106160.

https://doi.org/10.1016/j.polymertesting.2019.106160

[2] Józó M., Cui L., Bocz K., Pukánszky B.: Processing induced segregation in PLA/TPS blends: Factors and consequences. eXPRESS Polymer Letters, 14/8. (2020) 768-779.

https://doi.org/10.3144/expresspolymlett.2020.63

[3] Singh S., Santana-Pérez O., Rodriguez C., Oksman K., Maspoch M. L.: Mechanical behaviour of poly(lactic acid)/cellulose nanocrystal nanocomposites: A comparative study between conventional tensile test and small punch test. eXPRESS Polymer Letters, 14/12. (2020) 1127-1136.

https://doi.org/10.3144/expresspolymlett.2020.92

[4] Hajba S., Tábi T.: Cross effect of natural rubber and annealing on the properties of poly(lactic acid). Periodica Polytechnica Mechanical Engineering, 63/4. (2019) 270-277.

https://doi.org/10.3311/PPme.12825 
[5] Pölöskei K., Csézi G., Hajba S., Tábi T.: Investigation of the thermoformability of various D-Lactide content poly(lactic acid) films by ball burst test. Polymer Engineering and Science, 60. (2020) 1266-1277.

https://doi.org/10.1002/pen.25378

[6] Schwarzmann P., Illig: Thermoforming. 2. kiadás. Carl Hanser Verlag, München, 2019. 1-495.

[7] Ashter A.: Thermoforming of single and multilayer laminates. Plastic films technologies, testing, and applications. 1. kiadás. Elsevier, Oxford, 2014. $1-352$. 